\title{
Oscillatory flow reactor design for biological process
}

\author{
N. N. Azaini ${ }^{1}$ and N. Masngut ${ }^{*}$ \\ Faculty of Chemical \& Natural Resources Engineering, Universiti Malaysia Pahang, \\ Lebuhraya Tun Razak, 26300 Gambang, Pahang, Malaysia. \\ *Email: norfaezahtul@gmail.com, nasratun@ump.edu.my \\ Phone: +6095492880
}

\begin{abstract}
Oscillatory flow reactor (OFR) is a novel type of tubular reactor consisting of equally spaced orifice baffles (sometimes called doughnut baffles) fitted inside the column of the reactor. OFR can be used for biological and chemical processes such as crystallisation of paracetamol, biofuel production, and production of sterols in ester saponification reactions. The aim of the study is to design and fabricate the oscillatory flow reactor for the purpose of biological process. In order to achieve turbulence flow inside the reactor, parameters such as reactor, baffles dimension, and type of oscillation system were considered prior to the design work. Autodesk: AutoCAD ${ }^{\circledR} 2016$ was used to draw the reactor parts. The OFR was fabricated in the Faculty of Chemical and Natural Resources Engineering (FKKSA) workshop in Universiti Malaysia Pahang (UMP). A complete OFR consists of three main parts which are reactor column, baffles plate and oscillation system. The OFR column was made from 304 grade stainless steel with dimensions of $500 \mathrm{~mm}$ in height and $60 \mathrm{~mm}$ internal in diameter so that it can fit in an autoclave and can withstand high temperatures and pressures. Due to the OFR's capability of mixing and transferring oxygen in gas-liquid phase, it was be further tested to evaluate its capability as bioreactor including the characterisation test based on its ability to maintain sterility, fluid loss due to evaporation, and the temperature profile.
\end{abstract}

Keywords: Oscillatory flow reactor; baffles; oscillation; reactor design; biological process.

\section{INTRODUCTION}

Oscillatory flow reactor (OFR) has been studied for many years in various areas specifically related to fluid dynamics, heat and mass transfer, and residence time distribution [1]. For years, researchers have suggested that oscillatory flow in a baffle column has a high potential for process and product enhancement in a wide range of applications [2]. OFR can be operated either on a batch or continuous mode, which requires a net flow of substrate into the reactor and product removal at an equal rate [3]. For a batch OFR operation, the column orientation can be run either horizontally or vertically. The fluids oscillation is achieved either at the base by means of oscillation system such as diaphragms, bellows, and piston, or at the top by moving a set of orifice baffles up and down the column [4]. A standard OFR consists of a tube with an internal diameter of $10 \mathrm{~mm}$ to $150 \mathrm{~mm}$ [3]. Uniform mixing at low shear is produced by vortices as fluid is forced through each orifice baffle plate [3]. There are many advantages of using oscillatory flow mixing such as efficient dispersion for immiscible fluids, uniform particle 
suspension, gas-in-liquid dispersions, and multiphase mixing [1]. Geometrical parameters or physical dimensions are important in OFR design. Five geometrical parameters must be necessarily considered, which are baffle thickness $(\delta)$, inter-baffle spacing $(L)$, orifice diameter $\left(D_{o}\right)$, column diameter $(D)$, and baffle- free area ratio $(\alpha)$, as defined in Eq. (1).

$$
\alpha=\frac{D_{o}^{2}}{D^{2}}
$$

The shape and length of vortex formation are determined by inter-baffle spacing, $L$. To generate uniform and effective mixing, vortices require adequate space to expand and spread throughout the inter-baffle zones otherwise they may collide with other baffles before they are fully expanded. With suboptimal distance between the baffles, on the one hand, it could lead to undesired axial dispersion especially when operating continuously. On the other hand, super optimal distance could make the vortices to not propagate to the full volume of the inter-baffle region, thus producing stagnant regions [3]. According to Gaidhani et al. [5], altering baffle spacing using distances of 1, 1.5, and 2 times the column diameter $(D)$ affected fluid mixing. However, the most effective mixing was achieved when the baffle spacing was equivalent to $1.5 \mathrm{D}$. The width of vortices formed within inter-baffle zone is defined by $\alpha$ as shown in equation 1. For example, some studies made by Gough et al. [6] tested the reactor with $D=50 \mathrm{~mm}, L=0.7-3.3 D$, and $D_{o}=0.51-$ $0.69 D$, and found that $L=0.57 \mathrm{D}$ and $\alpha=0.63$ gave the optimum vortex size to achieve efficient mixing of a polymerisation suspension. Meanwhile, studies from Zhang et al. [7] showed $\alpha=0.19$ are the most appropriate value for dispersion of liquid-liquid solutions. However, $\mathrm{Ni}$ et al. [8] reported that the range of $\alpha$ with $0.20-0.35$ can maximise the fluid mixing effect and minimise the frictional losses. Higher values of $\alpha$ generate narrow vortices and consequently produce poor mixing. Hence, by reducing the orifice diameter $\left(D_{o}\right)$, the fluid is constricted to a great extent as it passes through each baffle, thus producing wide vortices and generating effective mixing conditions [3].

Baffle thickness $(\delta)$ was also evaluated by $\mathrm{Ni}$ et al. [9] in all types of operations, a 50-mm diameter OFR using thickness values of $1 \mathrm{~mm}$ to $48 \mathrm{~mm}$. It was found that thicker baffles resulted in vortex deformation due to an increase in cling time, but with the optimum thickness of $2 \mathrm{~mm}$, the generation of vortices was favoured. This was implemented for all types of operations including pharmaceutical, chemical, and biological processes. The objective of the research is to design and fabricate the oscillatory flow reactor for the purpose of biological process.

\section{METHODS AND MATERIALS}

\section{Design Considerations}

Several criteria were considered before designing the oscillatory flow reactor (OFR), such as the dimension, materials for construction of the reactor, number of ports and location of baffle train. The dimension of the reactor was designed to fit into the standard autoclave in FKKSA's laboratory for the purpose of sterilisation. Thus, the dimension must not exceed $420 \mathrm{~mm}$ diameter and $795 \mathrm{~mm}$ of height. Since the reactor needs to be sterilised repeatedly in the autoclave, the materials for the OFR must be able to withstand high temperature and pressure. Hence, the reactor column was made from 304 grade stainless steel with a thickness of $2 \mathrm{~mm}$ to ensure lasting durability and for easier fabrication compared to glass materials. It must also be able to withstand corrosion, especially when handling processes involving strong chemicals compared to acrylic. 
The overall OFR fabrication was constructed for vertical operations where the top plate was designed to have sufficient line openings for ventilation, anti-foam, media, inoculum, $\mathrm{pH}$ control, and gas sparging. The reactor must also have enough ports for sampling, $\mathrm{Ph}$, and dissolved oxygen (DO) probes. In this design, several ports were located on each side of the reactor column. Two sampling ports were located at one side of the reactor column while $\mathrm{pH}$ and $\mathrm{DO}$ probes ports were located at the other side of the column. Two sampling ports were located each at $73 \mathrm{~mm}$ and $250 \mathrm{~mm}$ measured from the bottom of the OFR. pH and DO ports were located $157 \mathrm{~mm}$ and $329 \mathrm{~mm}$, respectively, measured from the bottom of the reactor. As both $\mathrm{pH}$ and DO ports are interchangeable, the sampling, $\mathrm{pH}$, and $\mathrm{DO}$ readings could be taken at various locations along the length of the column.

Table 1. Specifications and its justification based on each parameter.

\begin{tabular}{|c|c|c|c|}
\hline Parameter & Symbol & Specification & Justification \\
\hline Baffle thickness & $\delta$ & $3 \mathrm{~mm}$ & $\begin{array}{l}\text { - Thinner baffles favoured the } \\
\text { generations of vortices } \\
\text { - The eddy forms can cling on the } \\
\text { edge of the baffles } \\
\text { - Easily fabricated and drilled } \\
\text { compared to thinner baffles }\end{array}$ \\
\hline Baffle spacing & $\mathrm{L}$ & $90 \mathrm{~mm}$ & $\begin{array}{l}\text { - Based on the optimal baffle } \\
\text { spacing 1.5D [10] } \\
\text { - Ensure a full expansion of eddies } \\
\text { generated and the vortices can } \\
\text { spread effectively throughout } \\
\text { inter-baffle zone }\end{array}$ \\
\hline Baffle open area & $\alpha$ & $25 \%$ & $\begin{array}{l}\text { The free baffle area was defined } \\
\text { as }\left(\mathrm{D}_{\mathrm{o}} / \mathrm{D}\right)^{2} \\
\text { - The free baffle area controls the } \\
\text { width of vortices within each } \\
\text { baffle in the OFR } \\
\text { - When the free baffles area is } \\
\text { large, the width of eddies will be } \\
\text { shallower, hence the mixing } \\
\text { within the OFR is lower [9] }\end{array}$ \\
\hline Orifice diameter & $\mathrm{D}_{\mathrm{o}}$ & $30 \mathrm{~mm}$ & $\begin{array}{l}\text { Based on optimal orifice diameter } \\
0.5 \mathrm{D}[9]\end{array}$ \\
\hline $\begin{array}{l}\text { i) Column internal } \\
\text { diameter }\end{array}$ & $\mathrm{D}$ & $60 \mathrm{~mm}$ & $\begin{array}{l}\text { The specifications were decided so it } \\
\text { could fit into autoclave in FKKSA's }\end{array}$ \\
\hline ii) Column height & $\mathrm{H}$ & $500 \mathrm{~mm}$ & laboratory \\
\hline
\end{tabular}

In addition, it was necessary for the baffle train to be placed as such that it would not obstruct the probes' electrode. This was also to ensure the accuracy and durability of the electrode. The bottom plate of the OFR was designed to endure the stress from repeated oscillation and must be leak-proof to prevent contamination. A diaphragm pump set was used as an oscillation system for the OFR. Attached to the set was a panel box that displayed the output of $\mathrm{DO}, \mathrm{pH}$, and temperature readings. The panel showed the readings of the probes based on its location at the OFR (Figures 1 and 2). $\mathrm{pH}$ and DO 
readings were taken using $\mathrm{pH}$ probes (Mettler Toledo) and DO probes (Extech Instrument) while the temperature was measured using a $450 \mathrm{~mm}$ long thermocouple, which basically read the temperature through the length of the column. In addition, the panel box had a setting for the control of oscillation frequency which represented the mixing intensity of the OFR. Table 1 shows the specifications and the justification in designing the OFR. Based on these criteria, the OFR design was drawn using Autodesk: AutoCAD ${ }^{\circledR} 2016$ and fabricated in the Faculty of Chemical and Natural Resources Engineering (FKKSA), Universiti Malaysia Pahang (UMP). Figure 1 shows the detailed specifications of the OFR.

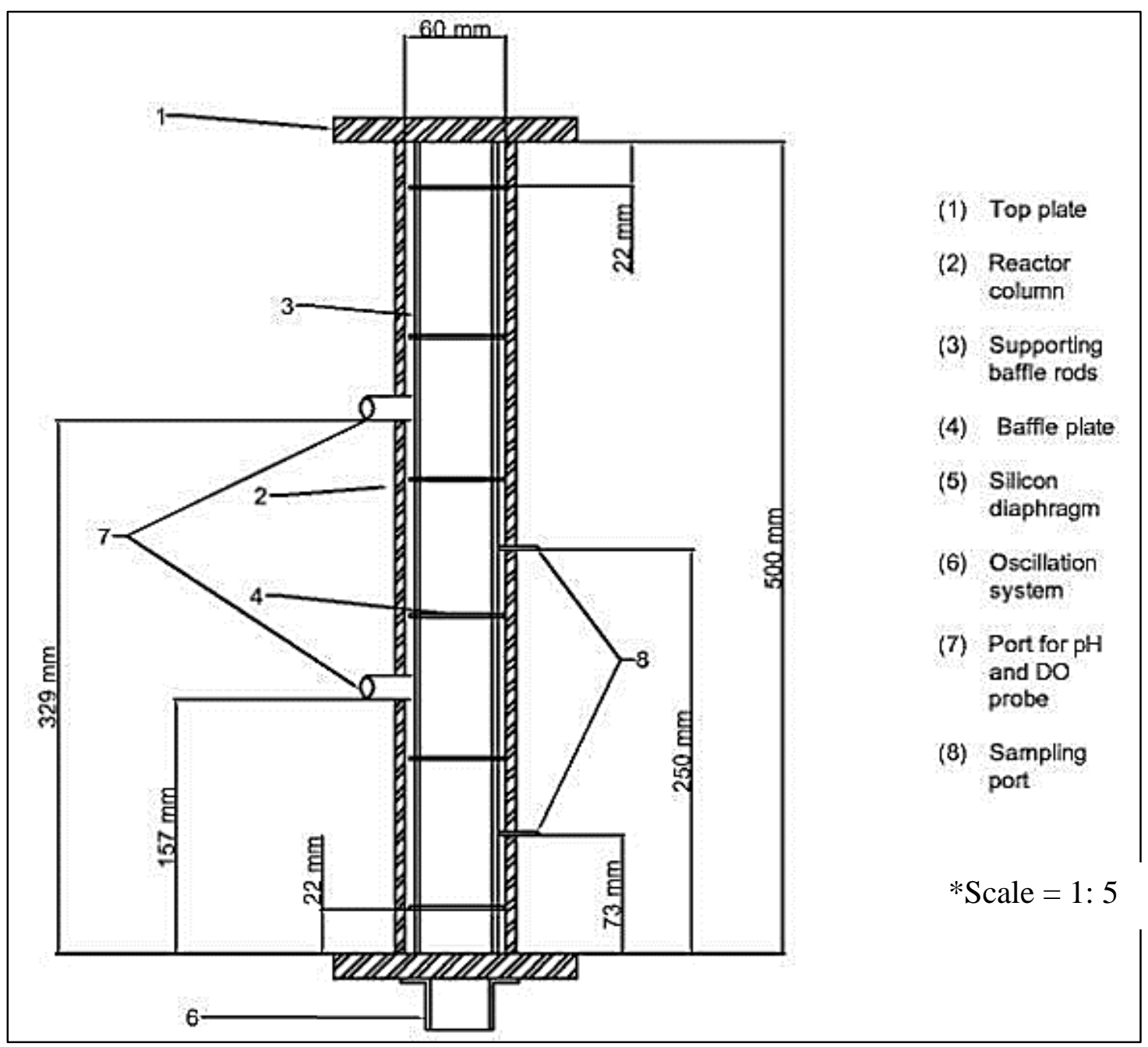

Figure 1. The OFR design

Based on Figure 1, most parts of the OFR were made from stainless steel. The orifice baffle plates were attached to the supporting baffle rods and altogether are called baffles train. On the reactor column, these were located for sampling ports and ports for $\mathrm{pH}$ and DO probes. Meanwhile, the remaining ports were located on the top plate of the OFR. The maximum working volume for the OFR to operate was $1.2 \mathrm{~L}$. This allowed 42 $\mathrm{cm}$ headspace inside the OFR. When the minimum working volume was $1 \mathrm{~L}$ that gave 35 $\mathrm{cm}$ headspace. To control the fluid temperature inside the OFR, a silicon tube flowed with water bath was wrapped around the reactor column. The fluid temperature inside the OFR 
was monitored regularly and manually controlled by adjusting the temperature of the water bath.

\section{Fabrication}

The main part of the OFR design and fabrication includes the reactor column, the top plate, baffles, the bottom plate, and the oscillation system.

\section{Reactor Column}

The reactor column was made from 304 grade stainless steel. The column had an internal diameter of $60 \mathrm{~mm}$ and length of $500 \mathrm{~mm}$. The column had two types of port sections, where each section contained two additional ports. The first section of the reactor (on the left side of the column) consisted of port for $\mathrm{pH}$ and DO probes and the second section (on the right side of the column) was for sampling ports. Figure 2 shows the configuration of the reactor column.

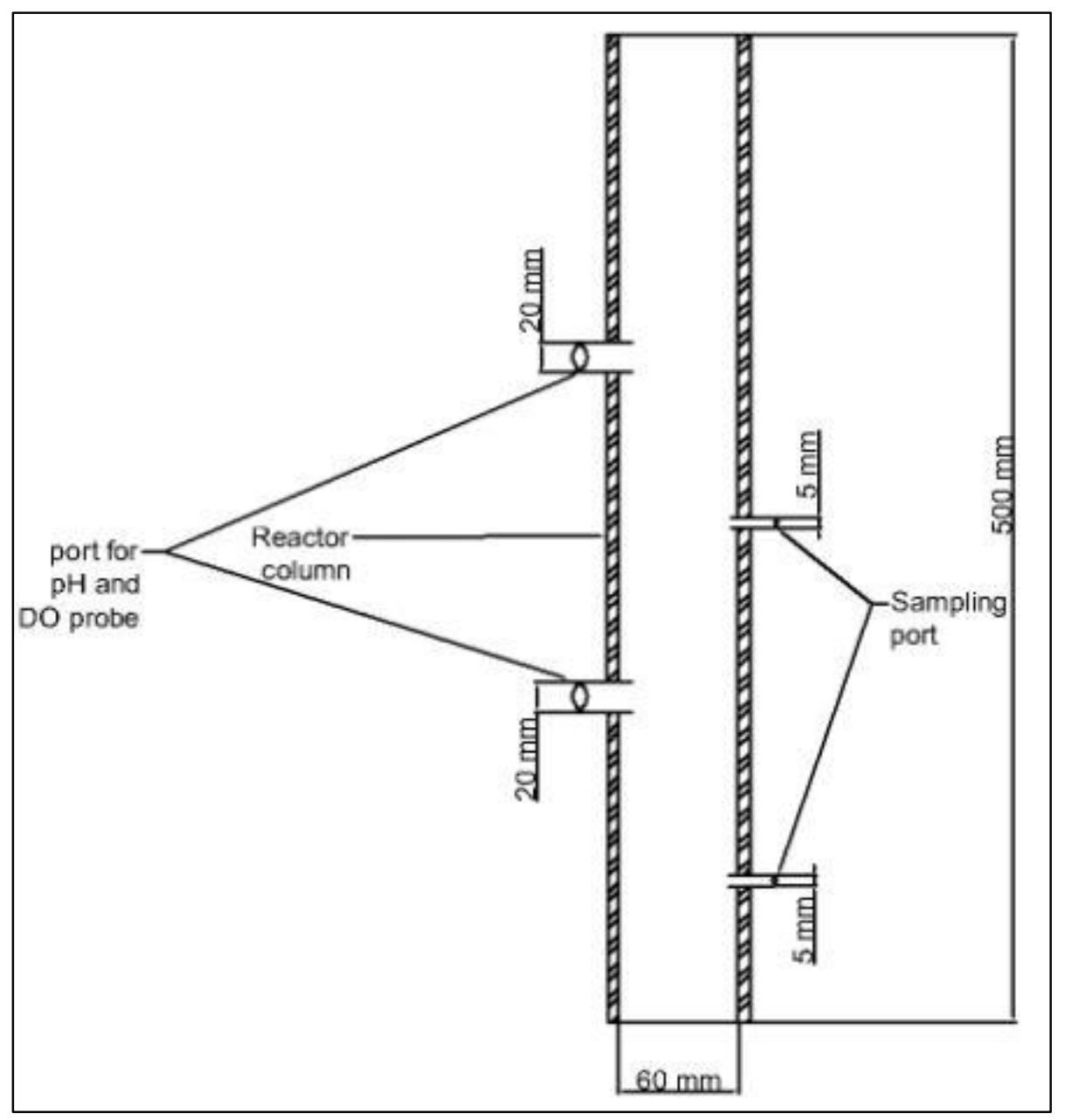

Figure 2. Configuration of the reactor column.

A $480 \mathrm{~mm}$ long sparging line was attached to the top plate of the OFR and pass through each orifice baffles plate along the length of the reactor column. This was done to ensure that the air bubbles would rise from the bottom of the reactor column and would give a higher retention time inside the OFR. The design of the sparging line does not 
interfere with the eddies formation due to the thickness of the sparger shaft with $2 \mathrm{~mm}$ diameter. Figure 3 shows the sparging line design inside the reactor column.

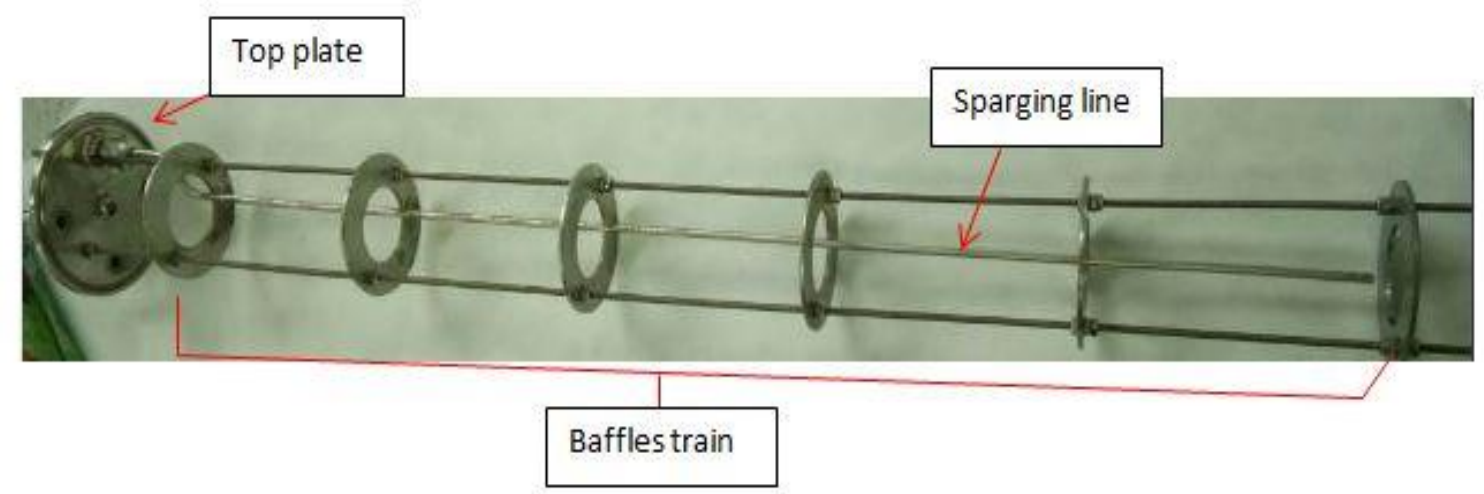

Figure 3. Design of sparging line inside the reactor column

\section{Top Plate}

The top plate was made from 304 grade stainless steel with $6.5 \mathrm{~mm}$ thickness for easy fabrication and drilling to provide the lines and openings for the OFR. The top plate was designed to have several openings for exhaust line in order to prevent pressure built up inside the reactor. In addition, there were openings for antifoam, acid and base, feed, ports for temperature probe and two additional holes to hold the baffle's support rods. Each opening (ports) had an inner diameter of $3 \mathrm{~mm}$. The top plate was connected to the reactor column using a clamp with PTFE gasket to prevent leakage. Figure 4 shows the configuration of the top plate.

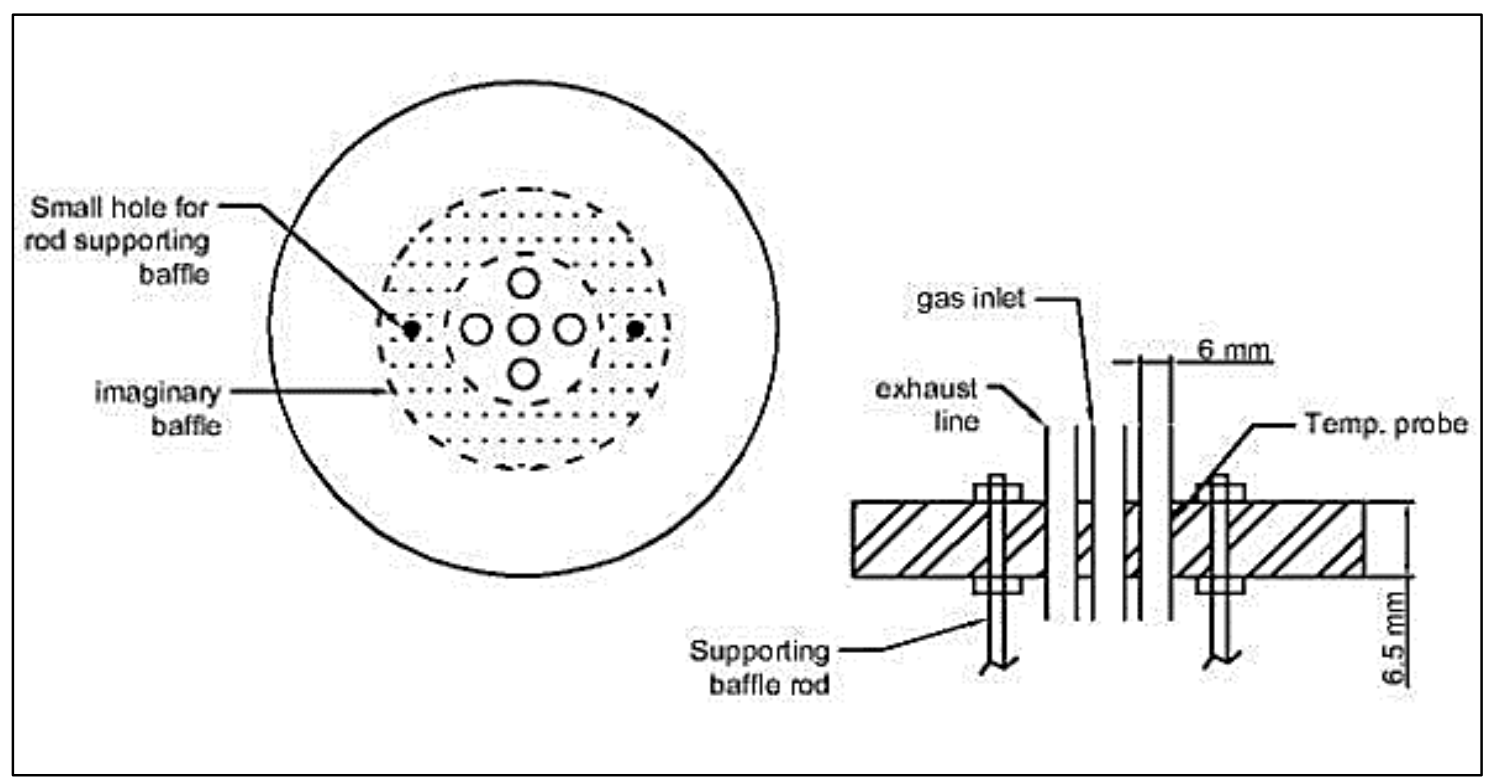

Figure 4. Configuration of the top plate.

\section{Baffles}

The type of baffles used in this study was a single-orifice baffle made from stainless steel. The baffle plate thickness $(\delta)$ of 2 to $3 \mathrm{~mm}$ was identified as the optimal value for good mixing as suggested by $\mathrm{Ni}$ et al. [9]. An orifice diameter of $30 \mathrm{~mm}$ was used to give a 
baffle area free ratio $(S)$ of 0.25 . Six baffle plates were arranged at a uniform distance of $90 \mathrm{~mm}$ along the length of the reactor column. All baffles were supported by a 3-mm diameter stainless steel support rods. Figure 5 shows the baffles plate design of OFR and Figure 6 shows the arrangement of baffles inside the reactor column.

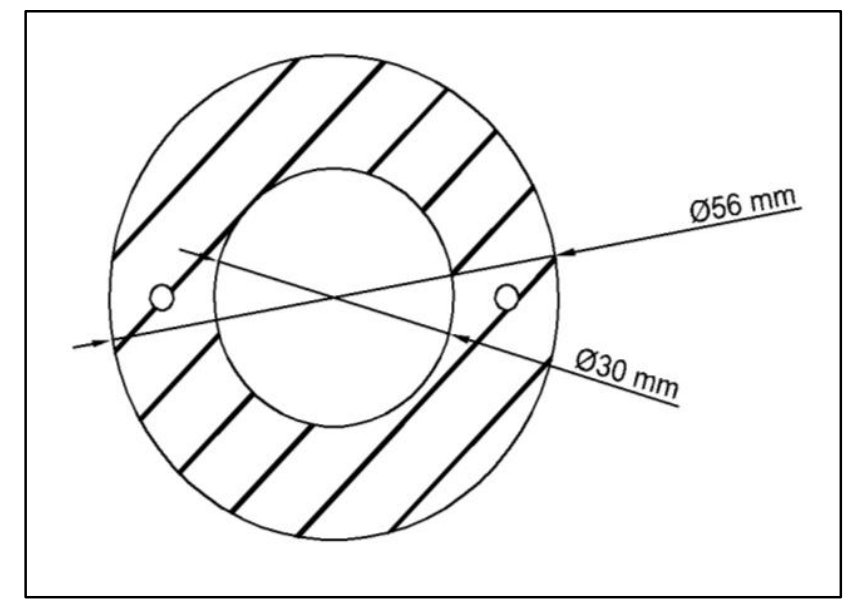

(a)

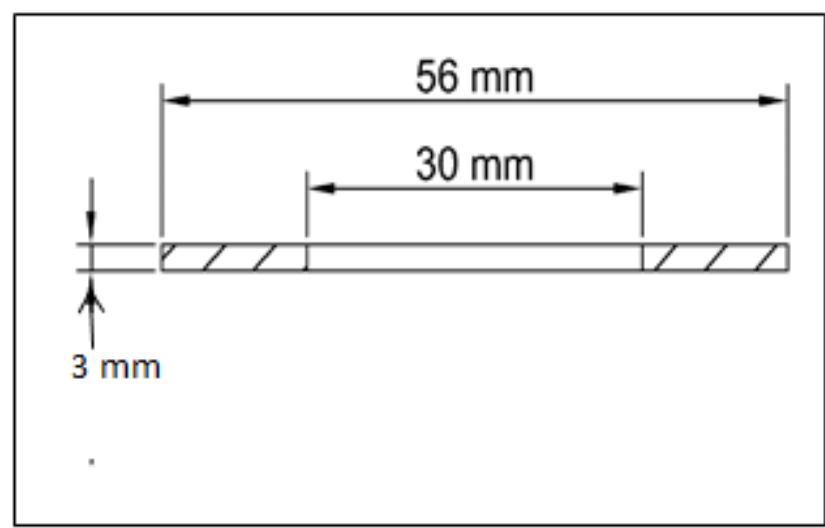

(b)

Figure 5. Configuration of the orifice baffle plate. (a) Top view, (b) Front view.

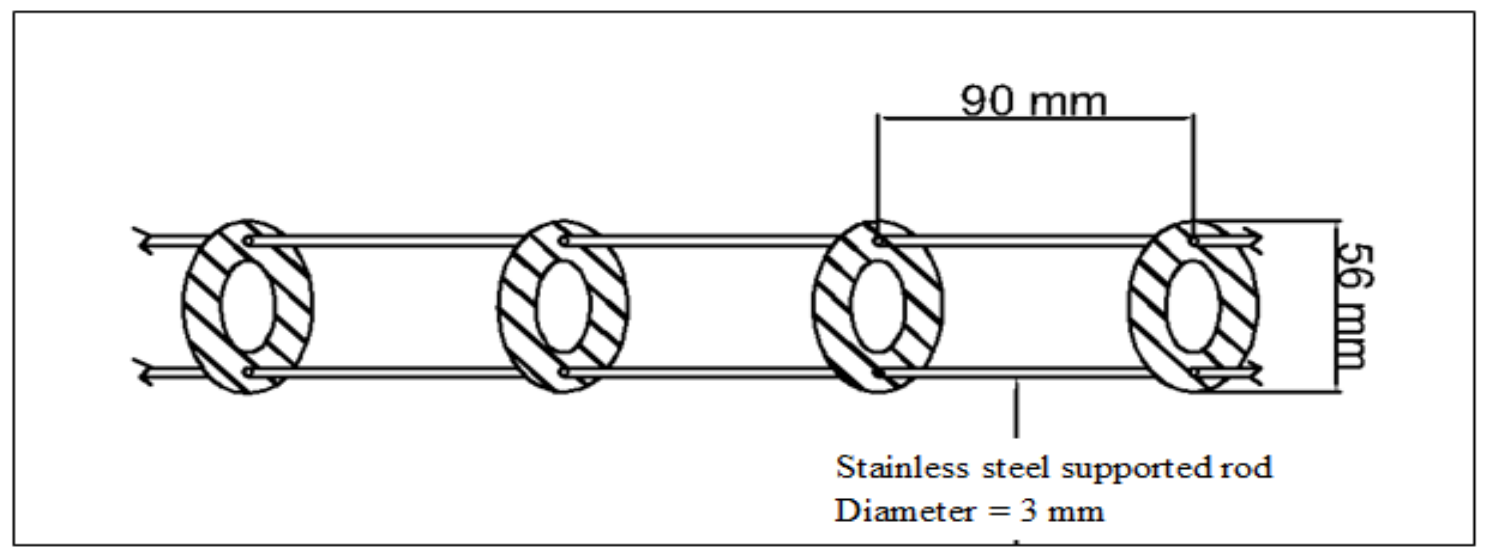

Figure 6. Arrangement of the orifice baffle plates. Number of baffle plates $=6$ plates. 


\section{Bottom Plate and Oscillation System}

The bottom plate was designed together with the oscillation system. A motor with oscillator drive and Teflon diaphragm were used for the oscillation system (diaphragm pump system). The diaphragm pump system operates by compressing and decompressing repeatedly to create a liquid oscillation in the reactor. The diaphragm pump system was assembled at the bottom of the reactor column. The oscillation system is driven by a Tekna Evo AKL 803 (SEKO) with 40W and 100-240 V. In this design, the oscillation frequency can be adjusted between 0.02 to $5 \mathrm{~Hz}$ with fixed oscillation amplitude of $8 \mathrm{~mm}$. Figure 7 shows the diaphragm pump system used in the OFR.
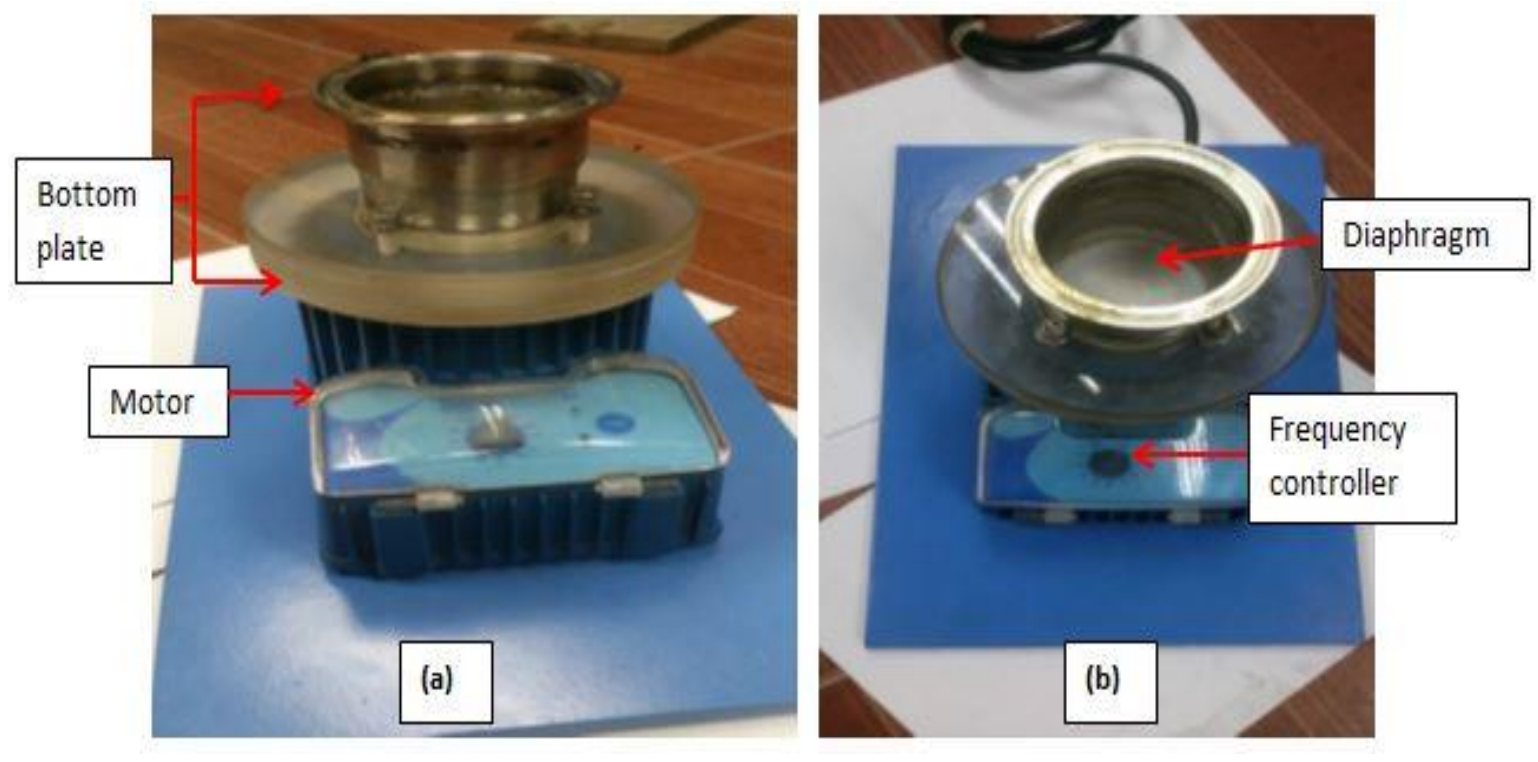

Figure 7. Diaphragm pump system. (a) Front view, (b) Top view.

\section{Mixing Intensities in the OFR}

The turbulence inside the OFR resulted from the design and dimension of each part of the reactor. The oscillatory Reynolds number, $R e_{o}$ (Equation 2) provides an indication of mixing intensity in the OFR and is precisely controlled by the frequency, $f$ and amplitude, $X_{o}$ of the OFR.

$$
R e_{o}=\frac{\rho 2 \pi f X_{O} D}{\mu}
$$

where $D$ is OFR diameter, $\rho$ is fluid density, and $\mu$ is dynamic fluid viscosity. The typical series of vortices are shown in Figure 8. The mixing in the reactor was provided by the generation and interruption of eddies that were created when the oscillating fluid interacted with the restrictions (i.e.: baffles). With repeated cycles of vortices formed, it thus created a strong motion that gives a uniform mixing in each inter-baffle region inside the OFR.

For flow separation to occur in the OFR, the oscillatory Reynolds number, $R e_{o}$ must be in a range of $50-100 . R e_{o}$ can be increased by increasing the amplitude or the frequency of the oscillation. In this design, the $R e_{o}$ can be manipulated by changing the oscillation frequency. The highest mixing intensities that can be produced by this design is $R e_{o}=18802$. This was limited by the frequency that can be achieved with the current design at a maximum of $5 \mathrm{~Hz}$ at a fixed amplitude of $8 \mathrm{~mm}$. Cultivation of aerobic 
microorganism cells requires efficient two phases mixing to ensure oxygen transfer from gas to the liquid phase. In this case, in the OFR, gas bubbles were generated by direct air sparging aimed at supplying oxygen to the culture medium with the help of media oscillations. Figure 9 shows the measured mass transfer coefficients, $\mathrm{K}_{\mathrm{L}} \mathrm{a}$ in the current OFR design at different $\operatorname{Re}_{o}(0,752,3008,9401,12409,18802)$. The experiment used nutrient broth (Merck) at an aeration rate of $1 \mathrm{vvm}$ with temperature controlled at $37^{\circ} \mathrm{C}$. This condition represented the $E$. coli fermentation condition.

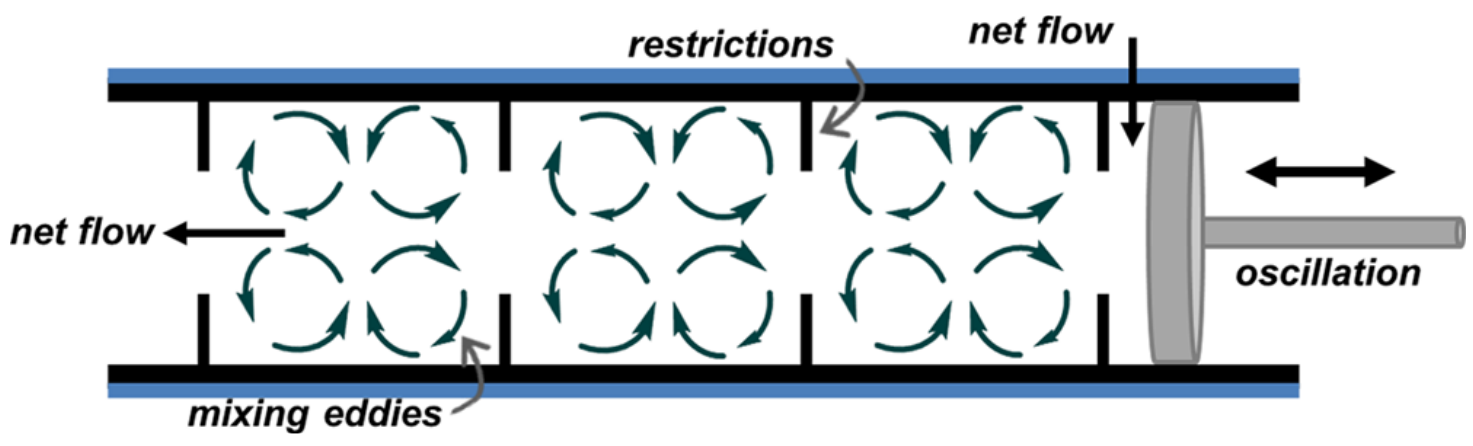

Figure 8. Mixing pattern in the OFR showing a series of vortices [11].

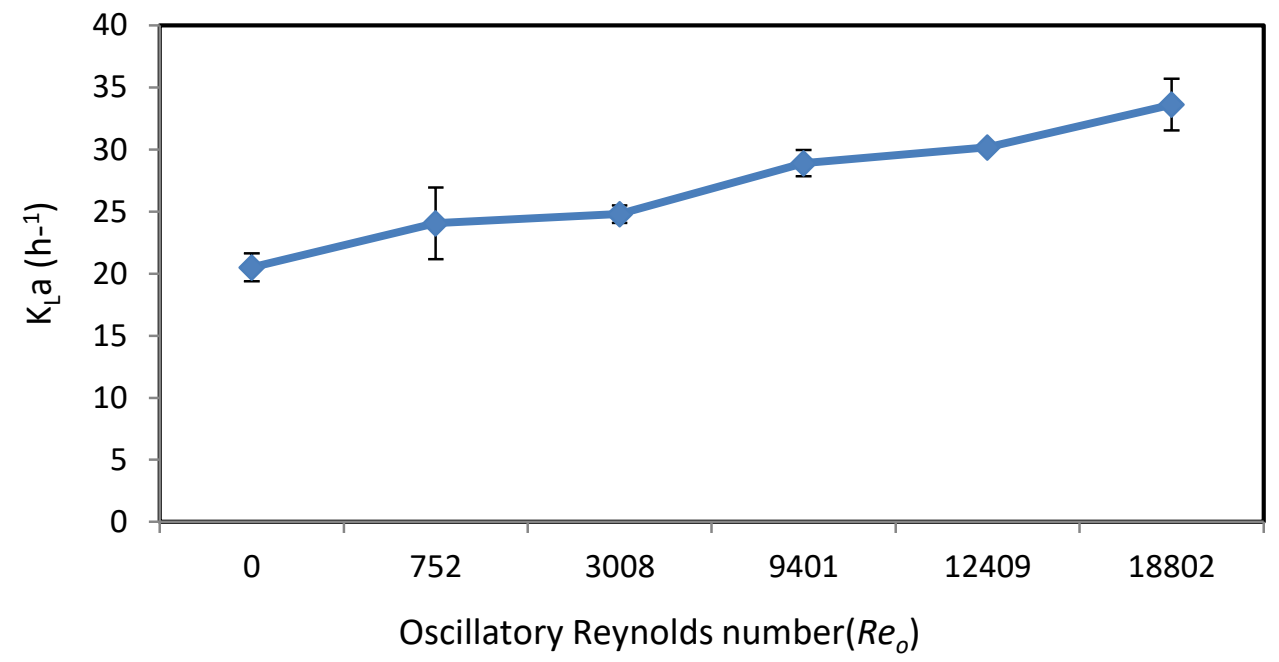

Figure 9. Mass transfer coefficient values in the OFR at different oscillatory Reynolds number.

Figure 9 shows the increasing trend of $\mathrm{k}_{\mathrm{L}}$ a as the $R e_{o}$ increased thus creating high mixing intensities. Intense mixing started at $R e_{o}=9401$, giving the $\mathrm{k}_{\mathrm{L}}$ a value of $28.9 \mathrm{~h}^{-1}$. Without oscillation, the measured $\mathrm{k}_{\mathrm{L}}$ a value was $20.5 \mathrm{~h}^{-1}$. At the highest $R_{o}$ of 18801 , which was achieved at $5 \mathrm{~Hz}$ oscillation frequency, the $\mathrm{k}_{\mathrm{L}}$ a was $33.6 \mathrm{~h}^{-1}$. This result demonstrates the ability of the OFR to produce the required $\mathrm{k}_{\mathrm{L}}$ a for bacteria fermentation (between 23-83 $\mathrm{h}^{-1}$ ) [12], through efficient mixing provided by the collision between liquid oscillation and the orifice baffles. This produces vigorous eddies and vortices in each inter-baffle region along the length of the OFR column. The gas bubbles were able to disperse and transfer the air throughout the OFR efficiently due to higher retention time 
inside the reactor column. Hence, it was convenient for the OFR to further perform as a bioreactor for example in the fermentation of an aerobic microorganism of E. coli.

\section{CONCLUSIONS}

Oscillatory flow reactor (OFR) was successfully designed specifically for biological processes such as fermentation of E.coli. Autodesk: AutoCAD ${ }^{\circledR} 2016$ was used to draw the OFR design. The OFR fabrication was done at Universiti Malaysia Pahang. Due to the OFR's capability of mixing and transferring oxygen in gas-liquid phase, it will be further tested to evaluate its capability as a bioreactor, including the characterisation test based on its ability to maintain sterility, fluid loss due to evaporation and the temperature profile throughout the fermentation course.

\section{ACKNOWLEDGEMENTS}

The authors would like to give credits to Universiti Malaysia Pahang for providing laboratory facilities and the Ministry of Higher Education (MOHE) for funding the research work under Fundamental Research Grant Scheme (FGRS) with grant number of RDU 150117.

\section{REFERENCES}

[1] Ghazi MTI. Heterogenous photocatalysis for chemicals manufacture: University of Cambridge, United Kingdom; 2005.

[2] Azhari TI, Ghazi M, Resul MFMG, Yunus R, Yaw TCS. Preliminary design of oscillatory flow biodiesel reactor for continuous biodiesel production from jatropha tryglycerides. Journal of Engineering Science and Technology. 2008;3:138-45.

[3] Abbott MS, Harvey AP, Perez GV, Theodorou MK. Biological processing in oscillatory baffled reactors: Operation, advantages and potential. Interface Focus. 2013;3:20120036.

[4] Jian H, Ni X. A numerical study on the scale-up behaviour in oscillatory baffled columns. Chemical Engineering Research and Design. 2005;83:1163-70.

[5] Gaidhani HK, McNeil B, Ni X. Fermentation of pullulan using an oscillatory baffled fermenter. Chemical Engineering Research and Design. 2005;83:640-5.

[6] Gough P, Ni XW, Symes KC. Experimental flow visualisation in a modified pulsed baffled reactor Journal of Chemical Technology and Biotechnology. 1997;69:321-8.

[7] Zhang YM, Ni XW, Mustafa I. A study of oil-water dispersion in a pulsed baffled reactor. Journal of Chemical Technology and Biotechnology. 1996;66:305-11.

[8] Ni X, Mackley MR, Harvey AP, Stonestreet P, Baird MHI, Rama Rao NV. Mixing through oscillations and pulsations - a guide to achieving process enhancements in the chemical and process industries. Chemical Engineering Research and Design. 2003;81:373-83.

[9] Ni X, Brogan G, Struthers A, Bennett DC, Wilson SF. A systematic study of the effect of geometrical parameters on mixing time in oscillatory baffled columns. Chemical Engineering Research and Design. 1998;76:635-42. 
[10] Brunold CR, Hunns JCB, Mackley MR, Thomson JW. Experimental observations on flow patterns and energy losses for oscillatory flow in ducts containing sharp edges. Chemical Engineering Science. 1989;44:1227-44.

[11] McGlone T, Briggs NEB, Clark CA, Brown CJ, Sefcik J, Florence AJ. Oscillatory flow reactors (ofrs) for continuous manufacturing and crystallization. Organic Process Research \& Development. 2015;19:1186-202.

[12] Mel M, Karim MIA, Salleh HM. The evaluation of ka values for recombinant escherichia coli fermentation producing $\beta$-glucuronidase enzyme. Journal of Applied Sciences. 2010;10:325-30. 